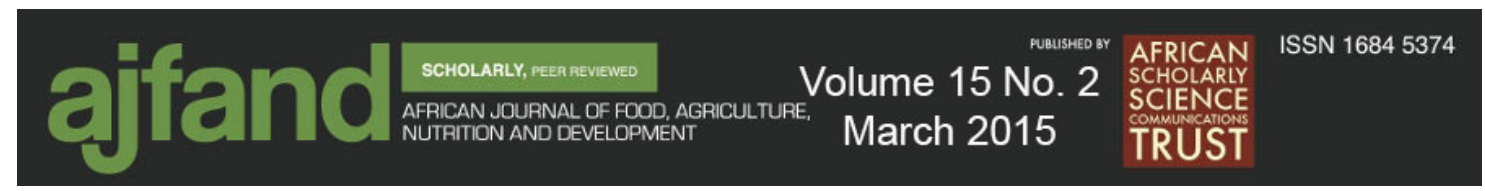

\title{
DIETARY PATTERNS AND NUTRIENT INTAKES OF A SOUTH AFRICAN POPULATION AND ASYMPTOMATIC PEOPLE INFECTED WITH HUMAN IMMUNODEFICIENCY VIRUS: THE TRANSITION HEALTH AND URBANISATION IN SOUTH AFRICA (THUSA) STUDY
}

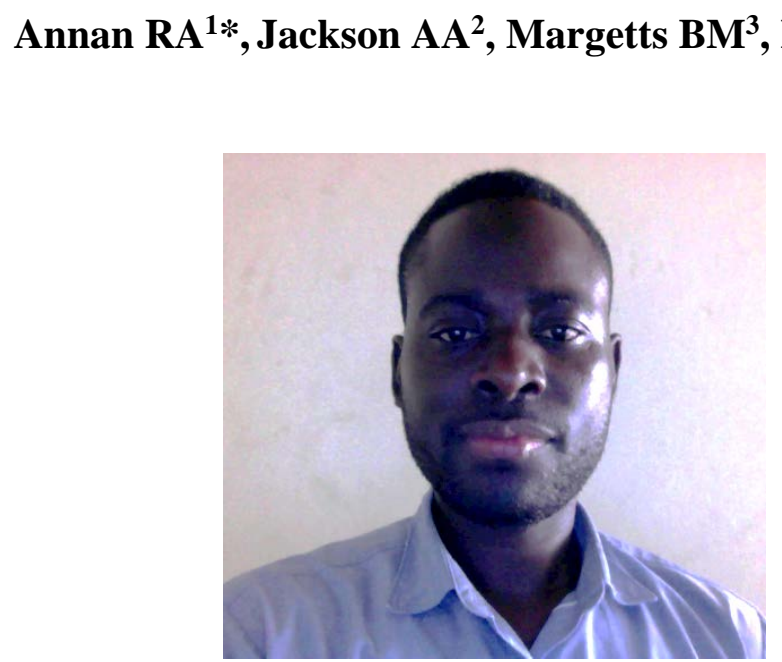

Reginald Annan

*Corresponding author’s email: reggie@imtf.org

${ }^{1}$ Department of Biochemistry and Biotechnology, College of Science, Kwame Nkrumah University of Science and Technology, Private Mail Bag, University Post Office, Kumasi, Ghana

${ }^{2}$ NIHR Nutrition Biomedical Research Unit, Southampton University NHS Trust, UK

${ }^{3}$ Institute of Human Nutrition, University of Southampton, Southampton, UK

${ }^{4}$ Centre of Excellence for Nutrition, North West University, Potchefstroom, South Africa 


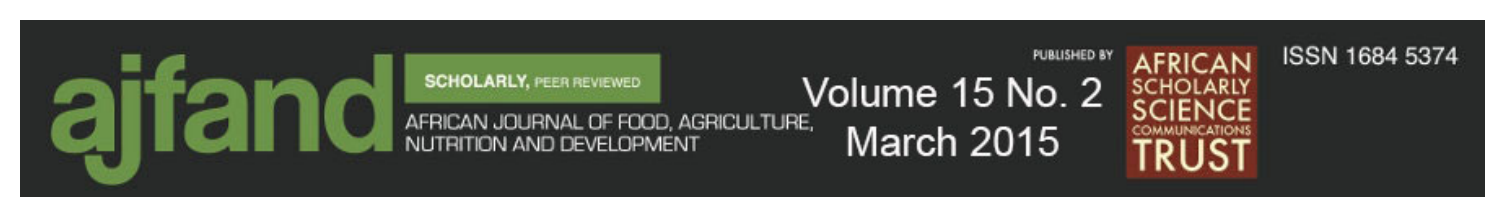

\section{ABSTRACT}

There is increased emphasis on the quality of food and the overall pattern of micronutrient intake as an integral consideration for food security particularly among people living with HIV/AIDS (PLWHA). However, limited data exist on food consumption and nutrient intakes for populations in sub-Saharan Africa. The study examined dietary patterns and their relationship with nutrient intakes in HIV uninfected (HIV-) and infected (HIV+) adults in North-West Province, South Africa. In this crosssectional study, dietary and nutrient intakes were assessed with Quantitative Food Frequency Questionnaire (QFFQ) and FoodFinder software, respectively. Dietary patterns were determined using Principal Component Analysis. Participants' scores for the dietary patterns were related to nutrient intakes using Spearman Rank correlation and Generalised Linear Modelling (GENLIN). Four main dietary patterns were found in each population. The first three patterns were similar between the HIV- and HIV+ populations: "animal-based", associated with intake of foods of animal origin; "recommended" associated with a varied diet; and "staple-based". The fourth pattern was described as either 'eggs-and-breakfast-cereals' for the HIV- group or 'legumesand-vegetables' for HIV+ group. Scores for animal-based pattern showed strongest correlations ( $\mathrm{r}$ ) with nutrient intakes for both populations, notably zinc $(\mathrm{r}=0.54)$, calcium $(\mathrm{r}=0.5)$, potassium $(\mathrm{r}=0.54)$, vitamin $\mathrm{A}(\mathrm{r}=0.5)$, and vitamin $\mathrm{C}(\mathrm{r}=0.5),(\mathrm{p}<0.001$ for all $)$. In the HIV+ group, the legumes-and-vegetables pattern was strongly associated with energy ( $r=0.64)$, vitamins $D(r=0.51), E(0.51)$ and $B_{1}(r=0.55)(p<0.001$ for all). Compared with the other patterns, the Staple-based and the recommended patterns showed the weakest associations with nutrient intakes. Generalised Linear Modelling confirmed stronger positive linear associations between scores of the animal-based diet and nutrients intake, compared with the other patterns. The findings suggest that the animal-based pattern was strongly associated with nutrients intake in both HIV + and HIV- populations. This raises the need for studies into dietary recommendations for promoting nutritional wellbeing for PLWHA in sub-Saharan Africa.

Key words: Dietary patterns; HIV/AIDS; THUSA, Nutrients 


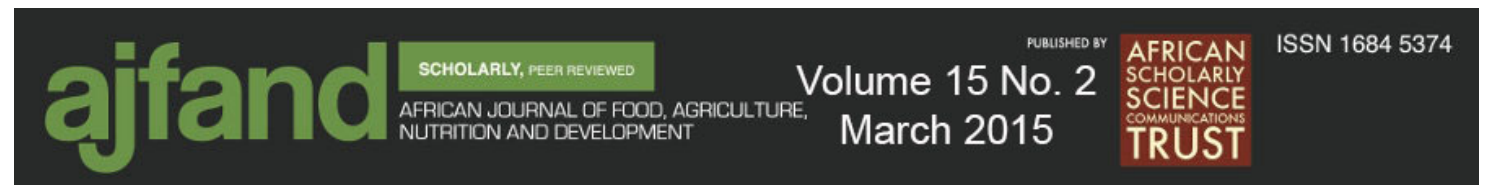

\section{INTRODUCTION}

The pattern of diet is an important determinant of overall pattern of nutrient intake, nutritional status and health among individuals and in populations but there is limited information on the patterns of habitual food consumption and nutrient intakes for populations in sub-Saharan Africa [1,2]. It is expected that these patterns vary widely and are changing with urbanisation and social mobility. For many, the quantity of available food is a matter of concern, but as with other parts of the world there is increased emphasis on the quality of the food and the overall pattern of micronutrient intake as an integral consideration for food security [3]. These concerns are amplified for People Living with HIV/AIDS (PLWHA).

Although it remains unclear the extent to which poor nutritional status predisposes an individual to HIV infection, it is widely agreed that the progression to AIDS and responsiveness to anti-retroviral therapy are modulated by nutritional status [4]. For PLWHA, there is enhanced immune impairment, secondary infection and severe wasting [5]. Inadequate dietary intake has been associated with wasting and poorer nutritional status in PLWHA, which contributes to enhanced disease progression [6]. Improving micronutrient status has been associated with lower mortality $[7,8,9]$ and improved CD4 cell count [8,9] and slower disease progression [8] in some studies and it can be concluded that poor nutritional status is likely to have an adverse effect on disease outcome in untreated PLWHA.

The introduction of Highly Active Anti-Retroviral Therapy (HAART) has contributed to the dramatic decline in HIV-related morbidity and mortality [10]. Treatment with ART can improve the clinical state by limiting viral replication and immune suppression [10]. However, patients with poor nutritional status who begin antiretroviral therapy have lower survival rates and more likely to die earlier than those with adequate nutritional status [4]. Adequate dietary intake and absorption are essential for achieving the benefits of antiretroviral treatment and reducing side effects of the drugs, whilst the therapy itself may increase appetite [4]. Dietary intake should therefore play an important role in the overall management and care for PLWHA.

Promotion of appropriate nutritional intake and healthy lifestyles is a strategy that was adopted by the International Conference on Nutrition for the global elimination or substantial reduction of malnutrition and diet-related diseases [12]. This led to development of the food-based dietary recommendations for healthy South Africans. The guidelines recommend people to eat a variety of foods, make starchy foods the basis of each meal and to eat lots of fruits and vegetables. The rest of the guidelines states that meat and dairy foods may be eaten daily, dried beans, peas, lentils, peanuts or soya should be eaten regularly, and sugars, fats and salt be used sparingly [13]. These recommendations are similar to what is currently recommended for PLHWA in South Africa [14].

The HIV epidemic is a major threat to development because it affects mainly the productive age-group and thus poses complex economic, social and cultural consequences on society. Sub- Saharan Africa continues to bear the greatest burden with 


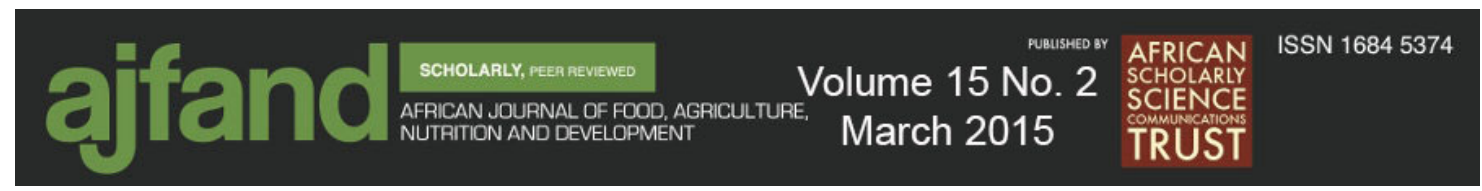

about 22.5 million of the 33.3 million currently estimated to be living with HIV in this region [15]. Given the magnitude of infections and current cost of anti-retroviral therapy, dietary advice will be an important consideration for the health and economic burden HIV imposes [16].

Much of the research on dietary considerations for PLWHA has been based on the use of nutrient supplements leading to guidelines, which are nutrient based rather than foodbased. These raise questions as to whether the food and nutrient intake of PLWHA are similar to the rest of the population, and whether or not there should be food- or nutrientbased guidelines which specifically address their needs. Any infection is likely to alter appetite, change nutrient requirements and increase nutrient losses, thereby predisposing to malnutrition [17]. The HIV infection and risk of secondary infection substantially increase nutritional vulnerability among PLWHA. Malnutrition exacerbates the effects of HIV by further weakening the immune system [18]. The overall effects of HIV infection such as weight loss, opportunistic infections and oxidative stress can modify the pattern of the need for nutrients and the dietary pattern which best fits the altered demands [18-20].

Dietary patterns describe what people eat because they capture the whole diet and are useful when developing guidelines or interpreting dietary data [21]. Data on how different dietary patterns influence nutrient intake and health for either non-infected or HIV-infected persons in Africa are needed. Information of this kind is an essential prerequisite for providing appropriate dietary guidelines for the general population or sub-groups such as PLWHA. The first challenge is to know what is currently consumed, and then determine the pattern that is more or less likely to be associated with health benefit, or disease progression. In this present study, researchers identified and compared patterns of dietary intake in non-infected and asymptomatic HIV infected adults, and their associations with nutrient intakes.

\section{MATERIALS AND METHODS}

\section{Population and study design}

This study was carried out in the North-West Province of South Africa as part of the THUSA study. Detailed description of the sampling and data collection procedures have been published elsewhere [22]. A cross-sectional comparative design was chosen due to resource limitations. A team consisting of scientists and Setswana-speaking field workers used both qualitative and quantitative methods to gather information. The North-West University statistics team helped to design a model for subject recruitment, based on data of population density, ensuring that subjects from all levels of urbanisation were included, and statistical power (80\%) was reached to show significant differences between subject groups. The sample consisted of 1854 healthy men and women, aged 15 years or more who were recruited from 37 randomly selected sites representing all the health districts in the province. Subjects aged below 15 years, pregnant and lactating women, those suffering from known and diagnosed diseases, such as heart disease, and diabetes, taking any form of chronic medication, and those with temperature above $37^{\circ} \mathrm{C}$ were excluded. At a later time, participants were screened 


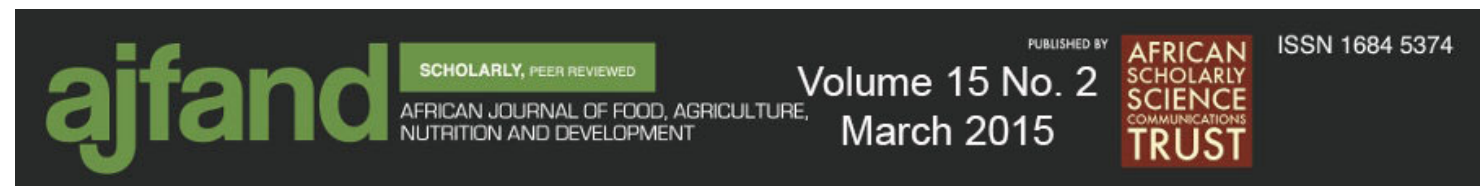

for HIV sero-positivity and 216 of the participants were found infected. Subjects were not on anti-retroviral therapy.

Dietary data were collected using a 145-item Quantitative Food Frequency Questionnaire (QFFQ), developed specifically for the study and validated against a 7day weighed food intake. The food intake data were analysed using Food Finder programme in order to determine nutrient intakes. The various items in the QFFQ were grouped into 20 food groups that adequately described them. A detailed description of the development, reproducibility and validity of the QFFQ has been published [23, 24, 25].

\section{Statistical analysis}

All analyses (descriptive, correlations and principal component analysis) were done using SPSS software, version 17.0.1 (SPSS Inc., Chicago IL, USA). Statistical significance was set at $\mathrm{p}<0.05$ for all analyses. Socio-demographic characteristics of the population by HIV status were compared and statistical differences determined. To determine the dietary patterns, PCA was performed on the 20 food groups in SPSS. The PCA used here has been described in detail elsewhere [26]. The number of patterns which best represented the food intake of the population were selected based on the Scree plot as well as the interpretability of the factor loadings for the components (patterns) derived from the PCA technique. The factor loading is the coefficient that explains the correlations of each food item with a particular component (pattern). The larger it is, the greater the contribution of that food item to that component (pattern). In this study, loadings below 0.2 were considered weak associations with the components and were omitted whereas those above 0.2 were considered more informative. Labels were given to each component to describe the underlying dietary pattern as much as possible in order to enable reporting and discussion of the results. As part of the PCA, for each component, each subject was allocated a score (dietary pattern score), which indicated how each subject was related to a particular component (pattern). The scores were calculated by multiplying the factor loadings by the corresponding standardised values for each food, and summing across the food types. Each score had a mean $=0$ and standard deviation $=1$. The higher the score, the closer a subject's diet was associated with the identified component (pattern).

\section{Determination of associations between dietary patterns and nutrient intake}

To enable the association between dietary patterns and nutrient intake to be explored, two different analyses were performed. First Spearman rank correlation was performed between dietary pattern scores and nutrient intake levels, controlling for the effect of energy intake, as well as other likely confounders such as age, gender, urbanisation and smoking status. Secondly, the dietary scores were split into thirds (lower, middle and upper thirds) and using the Generalised Linear Modelling (GENLIN) option in SPSS, the relative change in nutrient intakes by increasing thirds of dietary scores were estimated, using the lower thirds as reference. These estimates were adjusted for energy intake and the socio-demographic factors. The parameter estimates are presented as $95 \%$ CI. The rationale for GENLIN was to show the direction of associations between dietary pattern score categories and nutrient intakes. 


\section{Ethical approval}

This study was approved by the Ethics Committee of Potchefstroom University (approval no. 4M5-95) and informed written consents were obtained from the participants. The study was jointly funded by National Research Foundation, South African Medical Research Council, South African Sugar Association, The Dry Bean Producers Organization and Potchefstroom University.

\section{RESULTS}

\section{Characteristics of study participants by HIV infection status}

Of the total population of 1854, there were 1595 (88.1\%) HIV- and 216 (11.9\%) HIV+ subjects (Table 1). The prevalence of HIV infection decreased with age with the highest prevalence in the 25-34 years group. Prevalence of infection was higher in those who were not married, were Tswana speakers with lower educational attainment (below standard 6) and those with a household income less than 1000R (about £80). The prevalence was higher in urban compared with rural dwellers and in smokers compared with non-smokers. The HIV prevalence was significantly different $(\mathrm{p}<0.05)$ within the urbanisation level and age categories. There were no differences in the mean intakes for any of the food groups between those uninfected and infected with HIV.

\section{Dietary patterns}

Based upon PCA, four main components (patterns) of dietary intake for both HIV-and HIV+ populations were identified (Table 2). The first three were similar in both populations but the fourth was different. The similarity was shown by the similar foods for the patterns between the two populations as well as the factor loadings of the food groups ( $>0.05$ ). These patterns cumulatively explained about $44 \%$ of the variability in food intake in both populations. The first pattern recorded positive factor loadings of 0.6 and above for foods groups such as red meat, chicken, fish and dietary fat, and factor loadings 0.3 and below for fruits and vegetables in both groups. This component was broadly described as predominantly "animal-based", and explained $14.8 \%$ and $17 \%$ of the variability within the HIV- and HIV+ populations, respectively.

The second pattern recorded positive factor loadings for fruits (0.4) and vegetables (0.5), potato (0.6), bread (0.4), cereals $(0.3)$ and milk $(0.2)$; and negative factor loadings for fat (-0.7) and fish (-0.7) in the HIV+ group, similar to the HIV-, explaining $11.7 \%$ and $10 \%$ variability within the HIV- and HIV+, respectively. This pattern depicted a low fat but varied dietary pattern and was thus termed "recommended" dietary pattern since it described a pattern of dietary intake broadly similar to the guidelines recommended currently for South Africans $(13,14)$.

The third component recorded positive loadings for maize meal in the HIV+ group (0.6) and 'Samp' (a staple diet made from maize meal and rice) in the HIV-group (0.7). It was described as a "Staple-based" dietary pattern, explaining $9.3 \%$ and $8.6 \%$ of variability within the HIV- and HIV+, respectively.

The fourth pattern recorded positive factor loadings for egg (0.4), bread (0.5), breakfast cereal (0.5) and maize meal in the HIV-, explaining 8.6\% variability in this group and this component was denoted “egg-and-breakfast-cereals”. In the HIV+ population, 
positive factor loadings were for legumes $(0.5)$, potatoes $(0.4)$, vegetables $(0.3)$ and bread (0.2) and so this pattern was described as predominantly "legumes-andvegetables". The pattern explained $7.7 \%$ of variability in this group.

\section{Associations between dietary patterns and nutrient intake}

After adjusting for energy intake, age, gender, smoking and urbanisation status, the scores of the animal-based dietary pattern were more strongly correlated $(p<0.001)$ with both macronutrients and micronutrients than the other dietary patterns for both HIVand $\mathrm{HIV}+$ populations especially total fat $(\mathrm{r}=0.53)$, polyunsaturated Fat (PUFA) $(\mathrm{r}=0.42)$, zinc $(\mathrm{r}=0.54)$, calcium $(\mathrm{r}=0.54)$, potassium $(\mathrm{r}=0.5)$, iron $(\mathrm{r}=0.44)$, vitamins $\mathrm{A}$ $(\mathrm{r}=0.5), \mathrm{C}(\mathrm{r}=0.49)$, and $\mathrm{B} 9 \quad(\mathrm{r}=0.37)$ in the HIV+ population. $\mathrm{P}$ values for all were $<0.001$ (Table 3). The recommended and staple-based patterns showed the weakest and least significant associations with nutrient intakes compared with the rest (correlations were all 0.3 or less between these two patterns for all nutrients). For the HIV-group, the eggs-and-breakfast-cereals pattern was strongly associated with energy $(r=0.52)$, carbohydrate $(\mathrm{r}=0.54)$, vitamin $\mathrm{B}_{1}(\mathrm{r}=0.46)$ and polyunsaturated Fat (PUFA) ( $\left.\mathrm{r}=0.48\right)$, $(\mathrm{p}<0.001$ for all) whereas in the HIV+, the legumes-and-vegetables pattern was more strongly associated with energy $(\mathrm{r}=0.64)$, carbohydrate $(\mathrm{r}=0.66)$, vitamin $\mathrm{B}_{1}(\mathrm{r}=0.55), \mathrm{D}$ $(\mathrm{r}=0.51)$ and $\mathrm{E}(\mathrm{r}=0.51),(\mathrm{p}<0.001$ for all) than the animal, recommended and staplebased patterns.

\section{Linear associations between the dietary patterns and nutrient intakes}

In this section, all p values were less than 0.01 unless otherwise stated. Using GENLIN, significant positive linear associations were observed between the animal-based dietary score and all macronutrients in the HIV- population except carbohydrate that recorded negative linear associations (Tables 4). For the recommended pattern, dietary score showed significant positive linear associations with energy, total fat, saturated fat and fibre. For the staple-based, dietary score showed significant positive linear association with energy, total protein, carbohydrate, PUFA and fibre and negative association with saturated fat $(\mathrm{p}<0.05)$. For the egg-and-breakfast-cereals diet, scores showed positive linear associations with energy, total protein, carbohydrate, PUFA and fibre. Similar associations were observed in the HIV+ group (data not shown).

For the mineral elements and vitamins, animal-based dietary scores showed significant positive linear associations with almost all the nutrients assessed including calcium, iron, zinc, and vitamins $\mathrm{A}, \mathrm{B}_{2}, \mathrm{~B}_{3}, \mathrm{~B}_{5}, \mathrm{~B}_{9}, \mathrm{C}$, D and $\mathrm{E}$ irrespective of HIV status. For the recommended diet, dietary score showed significant positive linear relationships with $\mathrm{Ca}, \mathrm{Fe}(\mathrm{p}<0.05)$, K, vitamins $\mathrm{B}_{5}, \mathrm{~B}_{9}$ and $\mathrm{E}$ in the HIV- population and for only Ca and $\mathrm{K}$ in the HIV+ group. For the staple diet, scores recorded significant positive associations with vitamins $\mathrm{B}_{1}, \mathrm{~B}_{5}$ and $\mathrm{E}$ in the $\mathrm{HIV}-$ and with vitamin $\mathrm{B}_{5}$ in the HIV+ group. For the egg-and-breakfast-cereals pattern, dietary score recorded significant positive linear associations with $\mathrm{Fe}$, and vitamins $\mathrm{B}_{1}, \mathrm{~B}_{5}, \mathrm{~B}_{9}, \mathrm{D}$ and $\mathrm{E}$ intakes in the HIV-, whereas for legumes-and-vegetables, significant positive linear associations were observed with Zn, Fe, vitamins $\mathrm{B}_{5}$ and D in the HIV+ population. 


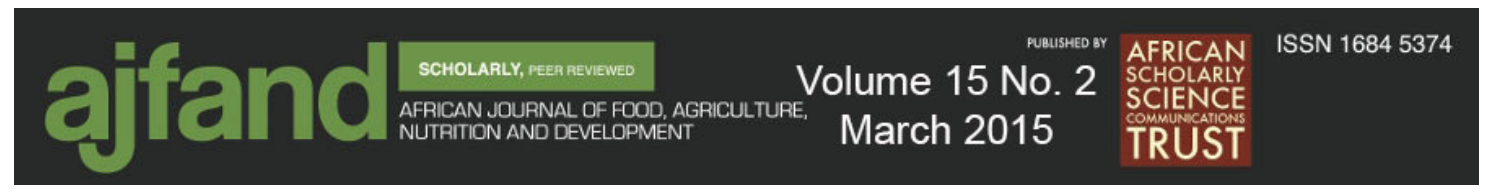

\section{DISCUSSION}

Comparing the four dietary patterns, the recommended pattern, represented a broader dietary pattern similar to the current recommended dietary guidelines for people in South Africa, including those infected with HIV. The pattern is also comparable to similar diets described as "healthy" in the literature, characterised by high fruits and vegetables and low dietary fat intake [27]. The animal-based diet on the other hand, was similar to the western type diet [28], described as predominantly animal and animalbased foods associated with elevated dietary cholesterol and saturated fat, and increased risk of cardiovascular disease and obesity [29]. A shift towards western type of diet has been reported in South Africa and found to be associated with increased disease risk [1]. It is on this basis that current dietary guidelines for South Africa are structured to encourage a varied and low fat dietary pattern, similar to that described as recommended in this study [13].

Distinct differences existed in the observed associations between scores of different dietary patterns and nutrient intakes. The animal-based diet showed the strongest association with intake of micronutrients. The recommended and staple-based dietary patterns showed the weakest associations with intake of both macro and micronutrients. The legumes-and-vegetables and egg-and-breakfast-cereals patterns on the other hand showed more positive associations with macronutrient intakes and some micronutrients. Further analyses using GENLIN, confirmed that all the four dietary patterns were generally associated with increased intake of macronutrients including dietary fibre. Some differences were, however, observed mainly regarding associations between the patterns and the different forms of fat. However, for the minerals and vitamins, the animal-based diet showed stronger linear associations with almost all nutrients assessed in both HIV- and HIV+ populations unlike the other patterns.

Together, these data show that the pattern of diet can exert an important influence on the overall pattern of nutrient intake in both HIV- and HIV+ people. This observation is particularly of greater significance in the cases of asymptomatic HIV+, where disease progression has been associated with poorer nutrient intake [7, 8]. In this study, HIV infected subjects whose dietary pattern was animal-based were more likely to have better nutrients intake, especially micronutrients, including fat. Hence an animal-based dietary may be more recommended. However, in a healthy population, where the goal of dietary intake is generally to reduce fat intake, maintain healthy weight, prevent obesity and cardiovascular risks, such dietary pattern may be less desirable although it is associated with better micronutrient intake.

Limited data exist on dietary patterns and nutrient intake for PLWHA [5]. Hendricks and colleagues found that asymptomatic PLWHA in the US who followed a fast food and fruit drinks dietary pattern had lower dietary fiber intake, highest viral load, and lowest Cluster of Differentiation 4 (CD4) cell count compared with people who followed a fruit, vegetable and low fat dietary pattern. The latter had higher protein, dietary fibre, micronutrient intakes, BMI and CD4 [5]. This suggests that a fruit, vegetable and low dairy dietary pattern favoured better nutrient intake. In our study however a predominantly animal-based dietary pattern was associated with better 


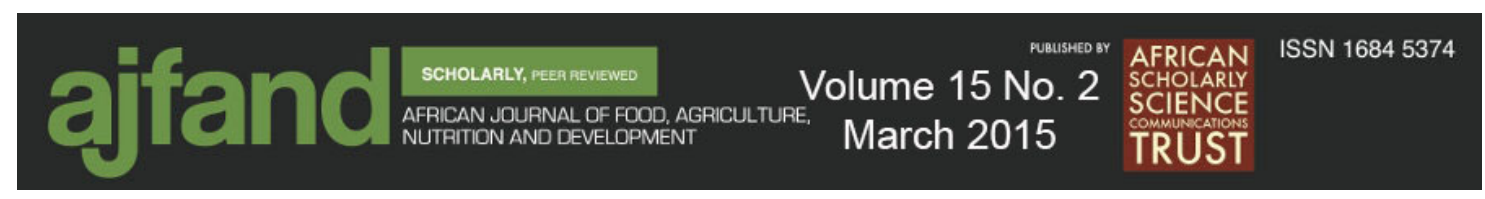

nutrient intake. Considering our findings and findings by Hendricks and colleagues [5], it is possible that a desirable dietary pattern for PLWHA may vary from population to population.

The PCA technique has been found useful in characterizing patterns of dietary intake in populations [30]. In this study, for each population, it was possible to account for higher variability (about 44\%) in food intake using PCA than other studies [30]. In PCA, the proportion of explained variance per factor decreases with the number of variables entered [26] and this study involved fewer food groups than in the study by Northstone and colleagues [30].

In conclusion, among four main dietary patterns observed in each study group, a predominantly animal-based dietary pattern was associated with better nutrients intake in general especially for micronutrients in the HIV+ population in contrast to a varied low fat dietary recommendation for this population. Whether these differences in nutrient intakes make a major difference to health in this population is not certain but the results present the need for an in-depth investigation of this in sub-Saharan Africa. This may have potentially important implications for policy in this region where the prevalence of HIV infection is staggering and the potential for nutrition in its management significant. 


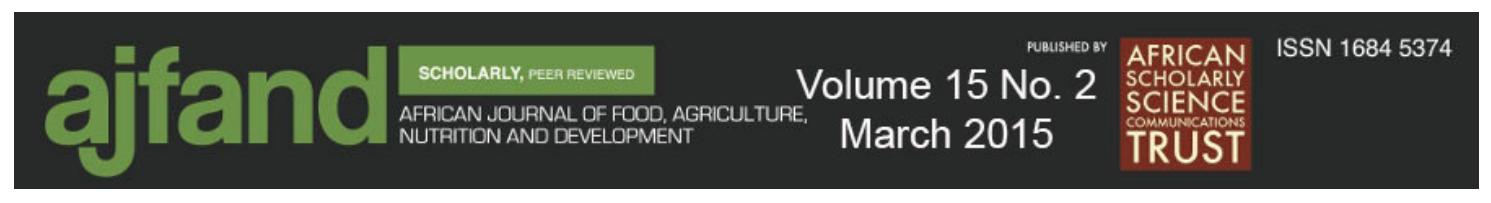

Table 1: Socio-demographic characteristics of study participants by HIV status

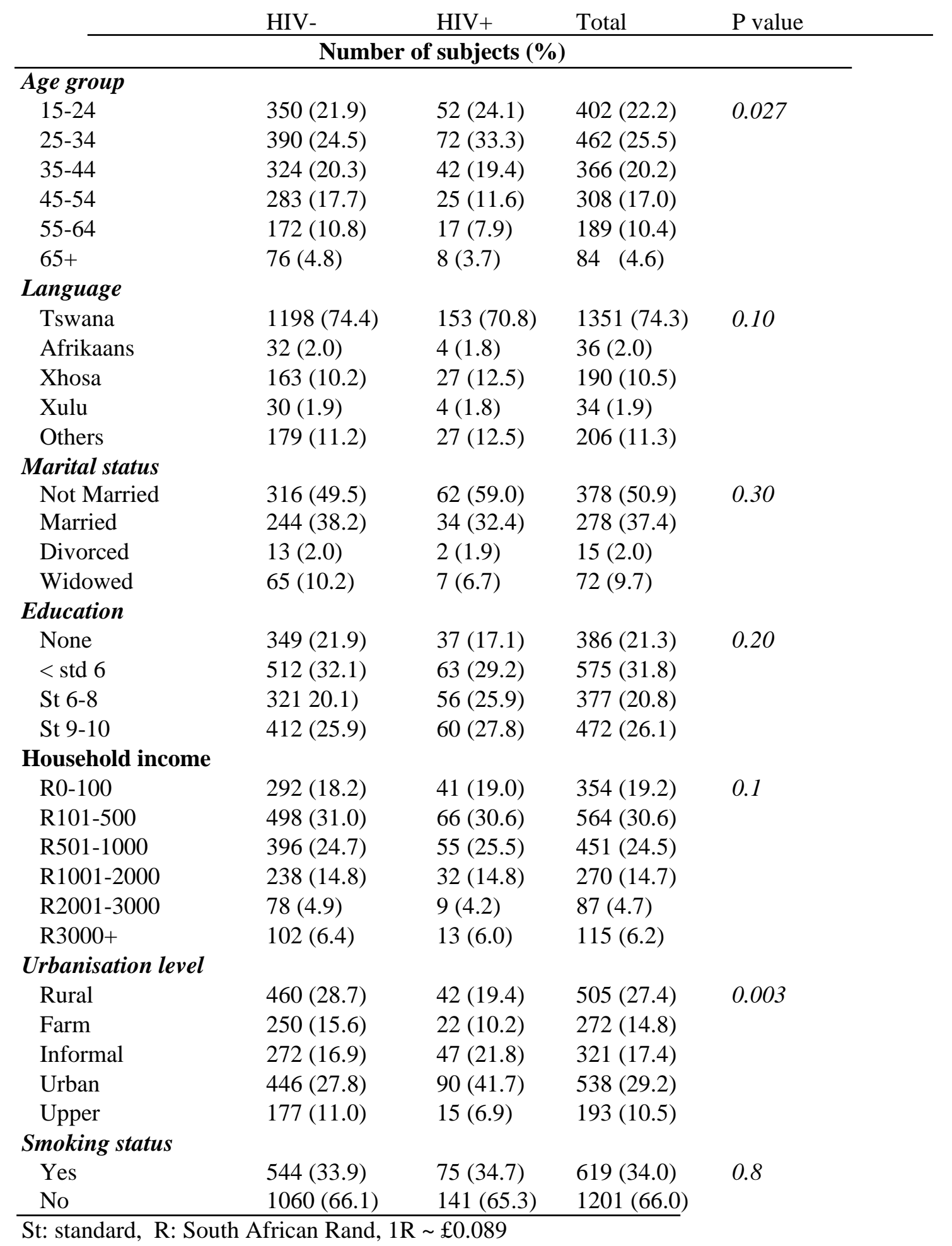




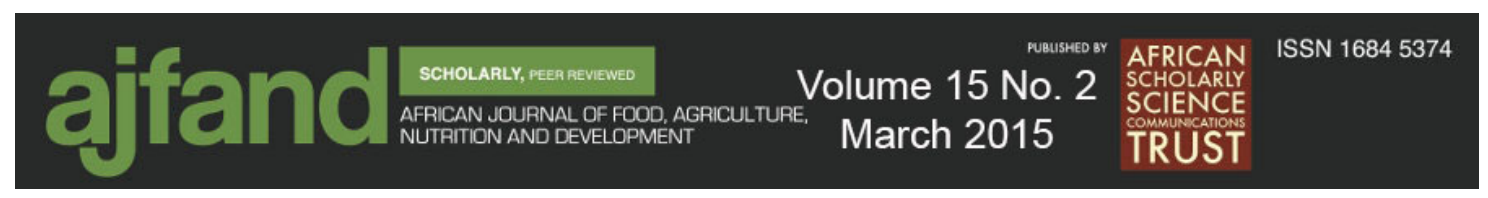

Table 2: Factor loadings and percent variation explained (\% VE) for first four dietary patterns by HIV status

\begin{tabular}{|c|c|c|c|c|c|c|c|c|c|c|}
\hline & \multicolumn{4}{|c|}{ (HIV-) } & \multirow[b]{2}{*}{$\% \mathrm{VE}$} & \multicolumn{5}{|c|}{ (HIV+) } \\
\hline & $\begin{array}{l}\text { Animal } \\
\text {-based }\end{array}$ & Recommended & $\begin{array}{l}\text { Staple- } \\
\text { based }\end{array}$ & $\begin{array}{l}\text { Egg-and- } \\
\text { breakfast- } \\
\text { cereals }\end{array}$ & & $\begin{array}{l}\text { Animal- } \\
\text { based }\end{array}$ & Recommended & $\begin{array}{l}\text { Staple- } \\
\text { based }\end{array}$ & $\begin{array}{l}\text { Legumes-and- } \\
\text { Vegetables }\end{array}$ & $\% \mathrm{VE}$ \\
\hline \% variation & 14.8 & 11.7 & 9.3 & 8.5 & & 17 & 10 & 8.6 & 7.7 & \\
\hline Milk & & & & -0.2 & 0.6 & 0.4 & 0.2 & -0.5 & & 0.8 \\
\hline Red Meat & 0.6 & & -0.3 & & 0.5 & 0.7 & & & -0.3 & 0.7 \\
\hline Chicken & 0.6 & & -0.3 & & 0.5 & 0.5 & & & -0.5 & 0.7 \\
\hline Fish & 0.7 & -0.7 & & & 0.9 & 0.8 & -0.7 & & 0.3 & 0.9 \\
\hline Legumes & & 0.3 & 0.7 & -0.2 & 0.6 & & & -0.4 & 0.5 & 0.5 \\
\hline Egg & & & & 0.4 & 0.3 & & & 0.4 & & 0.8 \\
\hline Fruits & 0.2 & 0.2 & -0.2 & & 0.5 & 0.3 & 0.4 & 0.2 & & 0.7 \\
\hline Vegetables & 0.3 & 0.3 & & & 0.5 & 0.3 & 0.6 & & 0.3 & 0.8 \\
\hline Potato & 0.4 & 0.4 & 0.2 & & 0.3 & & 0.5 & & 0.4 & 0.6 \\
\hline Maize meal & -0.2 & -0.3 & 0.3 & 0.4 & 0.5 & & -0.3 & 0.6 & & 0.5 \\
\hline Rice & 0.3 & 0.3 & & & 0.3 & 0.3 & & & & 0.7 \\
\hline "Samp" & & & 0.7 & & 0.6 & -0.2 & & & 0.4 & 0.6 \\
\hline Bread & & 0.3 & 0.2 & 0.5 & 0.4 & & 0.4 & 0.4 & 0.2 & 0.6 \\
\hline Breakfast cereal & & & & 0.4 & 0.3 & & 0.3 & & & 0.6 \\
\hline $\begin{array}{l}\text { Other cereal } \\
\text { (sorghum, oats \& } \\
\text { pasta) }\end{array}$ & & 0.5 & & & 0.4 & & 0.2 & & & 0.8 \\
\hline Fat & 0.8 & -0.7 & & & 0.9 & 0.8 & -0.7 & & 0.3 & 0.9 \\
\hline Sugar & & & & & 0.4 & & & & & 0.7 \\
\hline
\end{tabular}

\% VE refers to percentage variability explained by individual foods for different dietary components. Samp is a diet made from maize meal and rice 


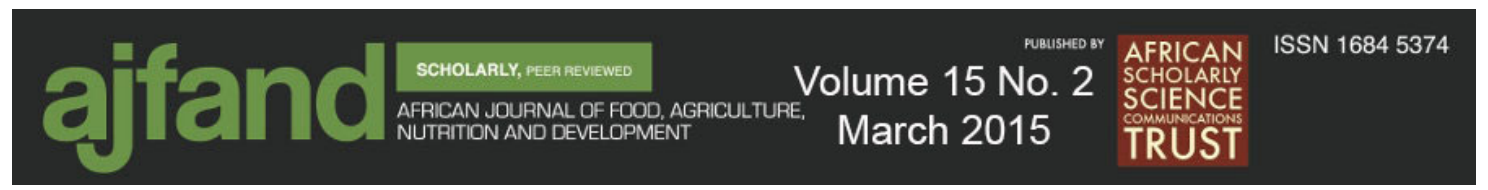

Table 3: Adjusted Spearman rank correlation coefficients (r) between patterns of dietary intake and nutrients by HIV status

\begin{tabular}{|c|c|c|c|c|c|c|c|c|}
\hline & \multicolumn{4}{|c|}{ HIV - } & \multicolumn{4}{|c|}{ HIV + } \\
\hline & $\begin{array}{l}\text { Animal } \\
\text { based }\end{array}$ & Recommended & $\begin{array}{l}\text { Staple } \\
\text { based }\end{array}$ & $\begin{array}{l}\text { Egg and } \\
\text { breakfast cereal }\end{array}$ & $\begin{array}{l}\text { Animal } \\
\text { based }\end{array}$ & $\begin{array}{l}\text { Recommend } \\
\text { ed }\end{array}$ & $\begin{array}{l}\text { Staple } \\
\text { based }\end{array}$ & $\begin{array}{l}\text { Legumes and } \\
\text { vegetables }\end{array}$ \\
\hline \multicolumn{9}{|l|}{ Macronutrients } \\
\hline Energy & 0.39 & 0.27 & 0.28 & 0.52 & 0.32 & & & 0.64 \\
\hline Total protein & 0.54 & 0.17 & 0.28 & 0.39 & 0.53 & & & 0.54 \\
\hline Total fat & 0.56 & 0.26 & 0.20 & 0.24 & 0.53 & $0.29 \dagger$ & & 0.39 \\
\hline Carbohydrate & 0.22 & 0.22 & 0.30 & 0.54 & & & & 0.66 \\
\hline Saturated fat & 0.50 & 0.31 & & $0.2^{*}$ & 0.54 & 0.29 & & $0.11 \dagger$ \\
\hline PUFA & 0.31 & $0.24 \dagger$ & & 0.48 & 0.42 & 0.22 & 0.26 & 0.37 \\
\hline Dietary cholesterol & $0.25 \dagger$ & & & 0.49 & 0.30 & & & 0.36 \\
\hline Fibre & $0.24 *$ & 0.31 & $0.27 \dagger$ & 0.45 & 0.35 & 0.32 & 0.30 & 0.31 \\
\hline \multicolumn{9}{|l|}{ Mineral elements } \\
\hline Calcium (Ca) & 0.47 & 0.24 & 0.21 & & 0.50 & $0.26 \dagger$ & & \\
\hline Iron $(\mathrm{Fe})$ & 0.44 & 0.22 & 0.16 & 0.43 & 0.44 & $0.19 *$ & & 0.47 \\
\hline Potassium (K) & 0.59 & 0.37 & 0.28 & 0.21 & 0.54 & 0.32 & & $0.31 \dagger$ \\
\hline Zinc (Zn) & 0.53 & 0.23 & 0.15 & 0.32 & 0.54 & $0.23 *$ & & 0.41 \\
\hline \multicolumn{9}{|l|}{ Vitamins } \\
\hline Vitamin A & 0.39 & 0.23 & & & 0.50 & & & \\
\hline Thiamine $\left(\mathrm{B}_{1}\right)$ & 0.27 & 0.19 & 0.23 & 0.46 & $0.27 *$ & & & 0.55 \\
\hline Riboflavin $\left(\mathrm{B}_{2}\right)$ & 0.38 & 0.20 & $0.09 \dagger$ & 0.21 & $0.26 \dagger$ & & & $0.28 \dagger$ \\
\hline $\operatorname{Niacin}\left(\mathrm{B}_{3}\right)$ & 0.44 & 0.15 & 0.17 & 0.33 & 0.32 & & & 0.46 \\
\hline Pantothenic acid $\left(\mathrm{B}_{5}\right)$ & 0.52 & 0.32 & 0.17 & 0.31 & 0.43 & $0.19 *$ & & 0.46 \\
\hline Folic acid $\left(\mathrm{B}_{9}\right)$ & 0.48 & 0.40 & 0.31 & 0.29 & 0.37 & $0.28 \dagger$ & & 0.36 \\
\hline Ascorbic acid (C) & 0.47 & 0.41 & & & 0.50 & 0.32 & & \\
\hline Vitamin D & 0.22 & $-0.1 \dagger$ & & 0.38 & $0.18^{*}$ & & & 0.51 \\
\hline Vitamin E & 0.31 & 0.18 & 0.23 & 0.41 & $0.25 *$ & $0.19 *$ & & 0.51 \\
\hline
\end{tabular}

All $\mathrm{P}$ values were less than 0.001 unless otherwise stated, $* \mathrm{P}<0.05$, $\uparrow \mathrm{P}<0.01$. Correlation coefficients with $\mathrm{P}>0.05$ have not been presented

Correlation adjusted for age, urbanization level, smoking status, gender and energy, PUFA: Poly Unsaturated Fatty Acid 


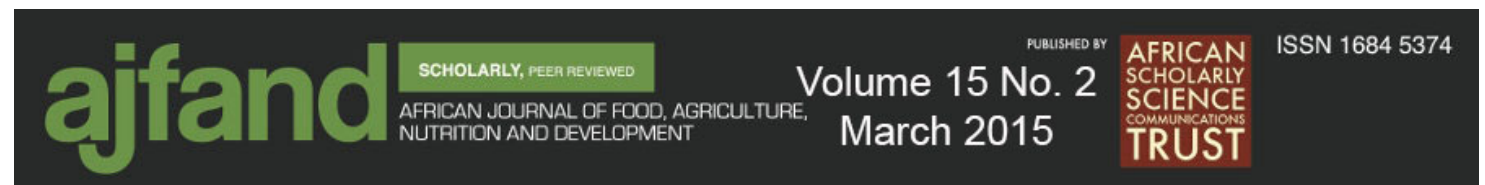

Table 4: Adjusted parameter estimates (co-efficient) and 95\% CI between thirds of dietary pattern scores and nutrient intakes

\begin{tabular}{|c|c|c|c|c|}
\hline & Animal-based & Recommended & Staple-based & $\begin{array}{l}\text { Egg and breakfast } \\
\text { cereals }\end{array}$ \\
\hline \multicolumn{5}{|c|}{ Energy } \\
\hline $\mathrm{T} 1$ & 0 & & 0 & 0 \\
\hline $\mathrm{T} 2$ & $0.04(0.03,0.06) \dagger$ & & $0.04(0.02,0.06) \dagger$ & $0.06(0.04,0.07) \dagger$ \\
\hline T3 & $0.05(0.03,0.08) \dagger$ & & $0.06(0.04,0.08) \dagger$ & $0.09(0.07,0.11) \dagger$ \\
\hline \multicolumn{5}{|c|}{ Total protein } \\
\hline $\mathrm{T} 1$ & 0 & & & 0 \\
\hline $\mathrm{T} 2$ & $0.14(0.12,0.16) \dagger$ & & & $0.04(0.01,0.06)^{* *}$ \\
\hline $\mathrm{T} 3$ & $0.25(0.22,0.29) \dagger$ & & & $0.04(0.01,0.08)^{* *}$ \\
\hline \multicolumn{5}{|c|}{ Total fat } \\
\hline $\mathrm{T} 1$ & 0 & 0 & & \\
\hline T2 & $0.19(0.14,0.23) \dagger$ & $0.09(0.04,0.13) \dagger$ & & \\
\hline T3 & $0.35(0.29,0.40) \dagger$ & $0.11(0.06,0.15) \dagger$ & & \\
\hline \multicolumn{5}{|c|}{$\begin{array}{l}\text { Total } \\
\text { carbohydrate }\end{array}$} \\
\hline $\mathrm{T} 1$ & 0 & & 0 & 0 \\
\hline $\mathrm{T} 2$ & $-0.03 \mathrm{NS}$ & & $0.07(0.04,0.10) \dagger$ & $0.09(0.07,0.12) \dagger$ \\
\hline $\mathrm{T} 3$ & $-0.12(-0.15,-0.08) \dagger$ & & $0.10(0.07,0.13) \dagger$ & $0.15(0.12,0.18) \dagger$ \\
\hline \multicolumn{5}{|c|}{ Poly Unsaturated } \\
\hline \multicolumn{5}{|c|}{ Fatty Acid (PUFA) } \\
\hline $\mathrm{T} 1$ & 0 & & 0 & 0 \\
\hline $\mathrm{T} 2$ & $0.14(0.09,0.20) \dagger$ & & $0.09(0.04,0.14)^{* *}$ & $0.08(0.02,0.13)^{* *}$ \\
\hline T3 & $0.24(0.17,0.30) \dagger$ & & $0.14(0.08,0.20) \dagger$ & $0.13(0.07,0.19) \dagger$ \\
\hline \multicolumn{5}{|c|}{ Saturated fat } \\
\hline $\mathrm{T} 1$ & 0 & 0 & 0 & \\
\hline $\mathrm{T} 2$ & $0.20(0.14,0.26) \dagger$ & $0.12(0.06,0.17) \dagger$ & $-0.07(-0.13,-0.02)^{*}$ & \\
\hline T3 & $0.37(0.30,0.44) \dagger$ & $0.11(0.05,0.17)^{* *}$ & $-0.12(-0.18,-0.06) \dagger$ & \\
\hline \multicolumn{5}{|c|}{ Cholesterol } \\
\hline $\mathrm{T} 1$ & 0 & & & \\
\hline $\mathrm{T} 2$ & $0.18(0.08,0.29)^{* *}$ & & & \\
\hline T3 & $0.46(0.33,0.58) \dagger$ & & & \\
\hline \multicolumn{5}{|c|}{ Fibre } \\
\hline $\mathrm{T} 1$ & 0 & 0 & 0 & 0 \\
\hline $\mathrm{T} 2$ & $0.10(0.05,0.14) \dagger$ & $0.06(0.02,0.12)^{* *}$ & $0.26(0.21,0.30) \dagger$ & $0.12(0.07,0.16) \dagger$ \\
\hline T3 & $0.19(0.13,0.24) \dagger$ & $0.26(0.22,0.31) \dagger$ & $0.26(0.21,0.30) \dagger$ & $0.23(0.18,0.28) \dagger$ \\
\hline \multicolumn{5}{|l|}{ Ca } \\
\hline $\mathrm{T} 1$ & 0 & 0 & & 0 \\
\hline $\mathrm{T} 2$ & $0.19(0.12,0.26) \dagger$ & $0.12(0.05,0.18)^{* *}$ & & $-0.20(-0.27,-0.13) \dagger$ \\
\hline T3 & $0.36(0.28,0.45) \dagger$ & $0.13(0.06,0.20)^{* *}$ & & $-0.34(-0.42,0.26) \dagger$ \\
\hline \multicolumn{5}{|r|}{ ( } \\
\hline $\mathrm{T} 1$ & 0 & 0 & & 0 \\
\hline $\mathrm{T} 2$ & $0.19(0.14,0.24) \dagger$ & $0.05(0.00,0.10)^{*}$ & & $0.07(0.02,0.12)^{* *}$ \\
\hline T3 & $0.24(0.18,0.30) \dagger$ & $0.06(0.01,0.11)^{*}$ & & $0.11(0.06,0.17) \dagger$ \\
\hline \multicolumn{5}{|r|}{ (1) } \\
\hline $\mathrm{T} 1$ & 0 & 0 & & \\
\hline $\mathrm{T} 2$ & $0.15(0.12,0.18) \dagger$ & $0.05(0.02,0.07)^{*}$ & & \\
\hline T3 & $0.26(0.23,0.30) \dagger$ & $0.12(0.09,0.15)^{* *}$ & & \\
\hline \multicolumn{5}{|c|}{ (l) } \\
\hline $\mathrm{T} 1$ & 0 & & & \\
\hline $\mathrm{T} 2$ & $0.17(0.13,0.21) \dagger$ & & & \\
\hline $\mathrm{T} 3$ & $0.29(0.25,0.34) \dagger$ & & & \\
\hline \multicolumn{5}{|c|}{ Vitamin A } \\
\hline $\mathrm{T} 1$ & 0 & & & \\
\hline
\end{tabular}




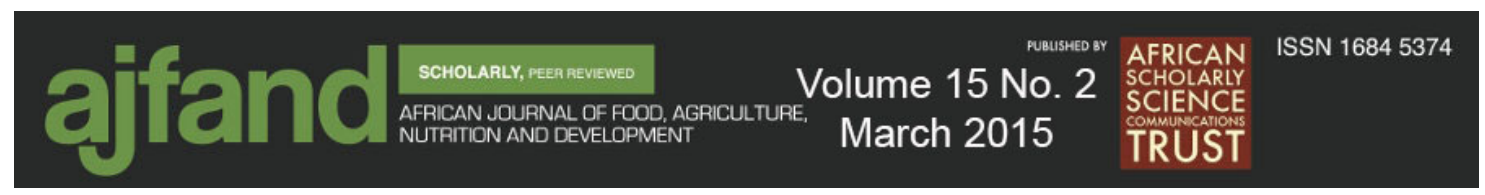

$\begin{aligned} \text { T2 } & 0.47(0.34,0.59) \dagger \\ \text { T3 } & 0.66(0.51,0.80) \dagger\end{aligned}$

Vitamin $\mathbf{B}_{1}$

T1

$\mathrm{T} 2$

T3

Vitamin $\mathbf{B}_{2}$

T1

$\mathrm{T} 2$

T3

Vitamin $B_{3}$

T1

$\mathrm{T} 2$

T3

\section{Vitamin $\mathbf{B}_{5}$}

$\mathrm{T} 1$

$\mathrm{T} 2$

T3

Vitamin $\mathbf{B}_{9}$

$\begin{array}{ll}\text { T1 } & 0 \\ \text { T2 } & 0.13(0.08,0.18) \dagger \\ \text { T3 } & 0.28(0.23,0.34) \dagger\end{array}$

Vitamin C

$\mathrm{T} 1$
$\mathrm{~T} 2$
$\mathrm{~T} 3$

T3

Vitamin D

$\begin{array}{ll}\text { T1 } & 0 \\ \text { T2 } & 0.16(0.03,0.29) * \\ \text { T3 } & 0.41(0.26,0.56) \dagger\end{array}$

Vitamin E

T1

$\mathrm{T} 2$

$\mathrm{T} 3$

$$
0
$$

$0.09(0.03,0.18)^{* *}$

$0.13(0.06,0.21)^{* *}$

$$
\begin{array}{ll}
0 & 0 \\
0.14(0.09,0.18) \dagger & -0.07(-0.12,- \\
0.20(0.14,0.26) \dagger & 0.03)^{* *} \\
& -0.09(-0.14,- \\
& 0.04)^{* *}
\end{array}
$$

0
$0.06(0.02,0.10)^{* *}$
$0.07(0.03,0.11)^{* *}$

0

$0.11(0.07,0.195) \dagger$

$0.15(0.10,0.19) \dagger$

$$
\begin{array}{ll}
0 & 0 \\
0.04(0.00,0.09)^{*} & 0.06(0.12,0.10)^{*} \\
0.11(0.06,0.16) \dagger & 0.10(0.05,0.15) \dagger
\end{array}
$$

$0 \quad 0$

$0.11(0.06,0.15) \dagger \quad 0.05(0.00,0.09)^{*} \quad 0.06(0.02,0.11)^{* *}$

$0.22(0.17,0.27) \dagger \quad 0.16(0.11,0.21) \dagger \quad 0.09(0.04,0.14)^{* *}$

0 $\begin{array}{ll}0.45(0.34,0.56) \dagger & 0.33(0.22,0.43) \dagger \\ 1.02(0.90,1.16) \dagger & 0.70(0.58,0.81) \dagger\end{array}$

$\begin{array}{ll}0.45(0.34,0.56) \dagger & 0.33(0.22,0.43) \dagger \\ 1.02(0.90,1.16) \dagger & 0.70(0.58,0.81) \dagger\end{array}$

Analysis adjusted for energy intake, age, gender, urbanization level and smoking; T1: Lower third, T2: middle third, T3: upper third; $* \mathrm{P}<0.05$, ${ }^{* *} \mathrm{P}<0.01, \dagger \mathrm{P}<0.001$; Note: The parameter estimates have no units. They are relative values which show relative change in nutrient intake by thirds of increase of dietary score. To simplify the table, values are presented for the HIV- group only since similar trends were found in the HIV+ group. Also non linear associations and insignificant linear associations have been omitted 


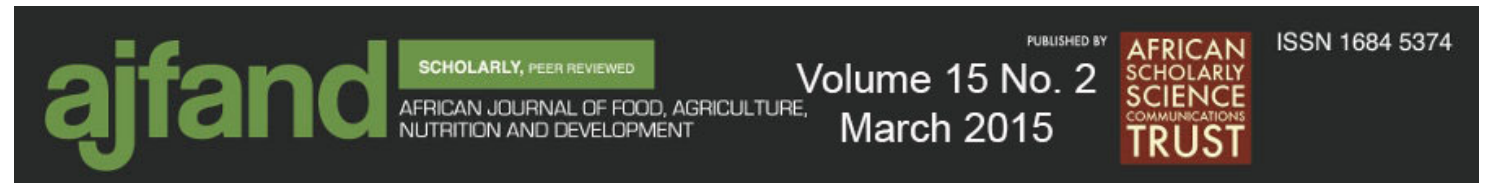

\section{REFERENCES}

1. Bourne LT, Lambert EVand K Steyn Where does the black population of South Africa stand on the nutrition transition? Public Health Nutr 2002;5:15762.

2. Nthangeni G, Steyn NP, Alberts M, Steyn K, Levitt NS, Laubscher R, Bourne $\mathbf{L}$, Dick $\mathbf{J}$ and $\mathbf{N}$ Temple Dietary intake and barriers to dietary compliance in black type 2 diabetic patients attending primary health-care services. Public Health Nutr 2002;5:329-38.

3. McCullough ML, Feskanich D, Stampfer MJ, Rosner BA, Hu FB, Hunter DJ, Variyam JN, Colditz GA and WC Willet Adherence to the Dietary Guidelines for Americans and risk of major chronic disease in women. Am J Clin Nutr 2000;72:1214-22.

4. Paton NI, Sangeetha S, Earnest A and R Bellamy The impact of malnutrition on survival and the CD4 count response in HIV-infected patients starting antiretroviral therapy. HIV Med 2006;7:323-30.

5. Hendricks KM, Mwamburi DM, Newby PK and CA Wanke Dietary patterns and health and nutrition outcomes in men living with HIV infection. Am J Clin Nutr 2008;88:1584-92.

6. Kotler DP Nutritional alterations associated with HIV infection. J Acquir Immune Defic Syndr 2000;25 Suppl 1:S81-S87.

7. Jiamton S, Pepin J, Suttent R, Filteau S, Mahakhanukrauh B, Hanshaoworakul $W$, Chaisilwattana $P$, Suthipinittharm $P$, Shetty $P$ and $S$ Jaffar A randomized trial of the impact of multiple micronutrient supplementation on mortality among HIV-infected individuals living in Bangkok. AIDS 2003;17:2461-9.

8. Fawzi WW, Msamanga GI, Spiegelman D, Wei R, Kapiga S, Villamor E, Mwakagile D, Mugusi F, Hertzmark E, Essex $M$ and DJ Hunter A randomized trial of multivitamin supplements and HIV disease progression and mortality. N Engl J Med 2004 ;351: 23-32.

9. Kupka R, Msamanga GI, Spiegelman D, Morris S, Mugusi F, Hunter DJ and WW Fawzi Selenium status is associated with accelerated HIV disease progression among HIV-1-infected pregnant women in Tanzania. J Nutr 2004;134:2556-60.

10. Shevitz AH and TA Knox Nutrition in the era of highly active antiretroviral therapy. Clin Infect Dis 2001;32:1769-75.

11. Hardon AP, Akurut D, Comoro C, Ekezie C, Irunde HF, Gerris T, Kglatwane J, Kwasa R, Maridadi J, Moroka M, Moyo S, Nakiyemba A, 
Nsimba S, Ogenyi R, Oyabba T, Temu F and R Laing Hunger, waiting time and transport costs: time to confront challenges to ART adherence in Africa. AIDS Care 2007;19:658-65.

12. FAO/WHO. International Conference on Nutrition. Food, Nutrition and Agriculture. 5-6. 1992. FAO, Rome.

13. South African Food Based Dietary Guidelines. The South African Journal of Clinical Nutrition 2001;14:S1-S80.14.

14. Department of Health South African National Guidelines on Nutrition for People Living with TB, HIV/AIDS and other chronic debilitating conditions (2001) Department of Health South Africa, South Africa.

15. UNAIDS. Joint United Nations Programme on HIV/AIDS (UNAIDS). Global Report UNAIDS report on the global AIDS epidemic 2010.

16. WFP/WHO/UNAIDS. UNAIDS Policy Brief: HIV, Food Security and Nutrition. 2008. UNAIDS, Switzerland.

17. Scrimshaw NS, Taylor CE and JE Gordon Interactions of nutrition and infection. Monogr Ser World Health Organ 1968;57:3-329.

18. Calder PC and AA Jackson Undernutrition, infection and immune function. Nutr Res Rev 2000;13:3-29.

19. Piwoz E and E Preble HIV/AIDS and nutrition: a review of the literature and recommendations for nutritional care and support in sub-Saharan Africa. 2000.

20. Semba RD and AM Tang Micronutrients and the pathogenesis of human immunodeficiency virus infection. Br J Nutr 1999;81:181-9.

21. Swain JF, McCarron PB, Hamilton EF, Sacks FM and LJ Appel Characteristics of the diet patterns tested in the optimal macronutrient intake trial to prevent heart disease (OmniHeart): options for a heart-healthy diet. J Am Diet Assoc 2008;108:257-65.

22. Vorster HH, Venter CS, Wissing MP and BM Margetts The nutrition and health transition in the North West Province of South Africa: a review of the THUSA (Transition and Health during Urbanisation of South Africans) study. Public Health Nutr 2005;8:480-90.

23. Macintyre UE, Venter CS and HH Vorster A culture-sensitive quantitative food frequency questionnaire used in an African population: 2. Relative validation by 7-day weighted records and biomarkers. Public Health Nutr 2001;4:63-71. 


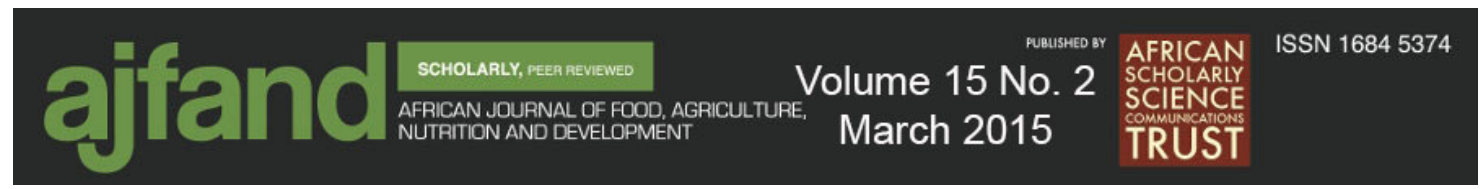

24. Venter CS, Macintyre UE and HH Vorster The development and testing of a food portion photograph book for use in an African population. $J$ Hum Nutr Diet 2000;13:205-18.

25. MacIntyre UE, Kruger HS, Venter CS and HH Vorster Dietary intakes of an African population in different stages of transition in the North West Province, South Africa: the THUSA study. Nutrition Research 22 (2002) 239256.

26. Smith LI A tutorial of Principal Component Analysis. 2002.

27. Crozier SR, Robinson SM, Borland SE and HM Inskip Dietary patterns in the Southampton Women's Survey. Eur J Clin Nutr 2006;60:1391-9.

28. Slattery ML, Boucher KM, Caan BJ, Potter JD and KN Ma Eating patterns and risk of colon cancer. Am J Epidemiol 1998;148:4-16.

29. Hu FB, Rimm EB, Stampfer MJ, Ascherio A, Spiegelman D and WC Willett Prospective study of major dietary patterns and risk of coronary heart disease in men. Am J Clin Nutr 2000;72:912-21.

30. Northstone K, Emmett PM and I Rogers Dietary patterns in pregnancy and associations with nutrient intakes. Br J Nutr 2008;99:406-15. 